University of Northern lowa

UNI ScholarWorks

Faculty Publications

Department of Educational Leadership \&

Postsecondary Education

8-2017

\title{
Spirituality and Contemporary Higher Education
}

Michael D. Waggoner

University of Northern lowa

Let us know how access to this document benefits you

Copyright (C2016 NASPA. The copyright holder has granted permission for posting.

Follow this and additional works at: https://scholarworks.uni.edu/elpe_facpub

Part of the Educational Leadership Commons

\section{Recommended Citation}

Waggoner, Michael D., "Spirituality and Contemporary Higher Education" (2017). Faculty Publications. 1. https://scholarworks.uni.edu/elpe_facpub/1

This Article is brought to you for free and open access by the Department of Educational Leadership \& Postsecondary Education at UNI ScholarWorks. It has been accepted for inclusion in Faculty Publications by an authorized administrator of UNI ScholarWorks. For more information, please contact scholarworks@uni.edu. 


\title{
Spirituality and Contemporary Higher Education
}

\author{
Michael D. Waggoner, University of Northern Iowa ${ }^{a}$
}

\section{Abstract}

Though religion played a central role in the founding of U.S. higher education, over the centuries, its influence was diluted by competing secular emphases. In recent decades, religion has seen a resurgence in academic and co-curricular attention on campuses. In addition, a spirituality not based on religion has gained increasing attention. The aim of this article is to provide an overview of the phenomenon of spirituality in contemporary higher education. The author discusses the recent appearance of spiritualty on campus, relates what research says about the potential benefits of and challenges in addressing spirituality in higher education, and examines some of the ways in which it is being addressed on U.S. college campuses.

We have all heard people say, "I'm spiritual, but not religious." What does this mean, and why is this distinction important? Should such a sentiment factor into any work of colleges and universities today?

It is well established that higher education in the United States began with a distinctly religious character. While the sponsors of the settling of colonial British America had strong economic expectations of the land and their investments, most who did the settling were religious dissenters from England seeking the freedom to practice their particular kind of protestant Christianity. Their institutions, particularly their colleges, reflected the religious dispositions of these settlers. The ensuing 400 years brought an unparalleled and sophisticated constellation of higher education institutions. Some of our current colleges and universities retain the religious flavor of these earliest institutions, but most have transformed into private and public secular institutions whose individual ethos varies with respect to its reception and treatment of religion and its more recent permutation, spirituality.

Much excellent scholarship has been produced on religion in higher education in the last 20 years, most recently the Jacobsens' No Longer Invisible: Religion in University Education (Jacobsen \& Jacobsen, 2012). Similarly the last decade has seen a growth in the literature on spirituality in higher education. The purpose of this article is to provide an overview of the phenomenon of spirituality in contemporary higher education. I discuss its recent appearance on campus, relate what research is telling us about the potential benefits of and challenges in addressing spirituality in higher education, and examine some of the ways in which it is being addressed on U.S. college campuses.

\footnotetext{
${ }^{a}$ Michael D. Waggoner (mike.waggoner@uni.edu) is professor of postsecondary education at the University of Northern Iowa and editor of Religion \& Education.
} 


\section{The Provenance of Contemporary Spirituality}

Spirituality has been predominantly, though not exclusively, associated with religion since rudimentary forms of religion appeared thousands of years ago. Idiosyncratic sets of rituals, practices, and beliefs coalesced within geographically scattered groups as they separately sought to make sense of life in their time and place and to provide guidance for how to live with one another. These systems often involved some supernatural being or spirit as well as the respective spirits of the individuals of that group. Some of these groups grew in popularity, most often through the work of charismatic leadership. Around 450 BCE, however, the Greeks developed philosophical bases for individual and group life that were independent of religion and gods. Though these ideas have remained in the minority they have survived, with further amplification by successive generations of interlocutors, as bases for modern secular spiritual and secular approaches to the moral life that need not involve religion (Barnes, 2012).

The current interest in spirituality apart from religion derives from two trends: (a) a growing dissatisfaction by many with religious systems that are seen as less and less relevant explanations of and guidance for modern life, and (b) perceived alternative means to achieve personal fulfillment grounded in the authority of and care for one's self. People still want experience that can help provide meaning for life and frameworks for moral interactions with fellow humans, but an increasing number no longer see religion as a means to that end. This is not to say that religion is passé; quite the contrary, it is alive, thriving, and still the dominant force in things spiritual, but those identifying as "nones," that is, no religious affiliation, have been rising and are now at $23 \%$ of the U.S. population (Lipka, 2015).

Our contemporary ideas about spirituality have been shaped by developments over the last 50 years. A thorough treatment of this social and intellectual history is beyond the scope of this current article, but we should take note of several trends that have cumulatively contributed to current thinking about religion and spirituality.

- Eastern immigration following the Immigration Act of 1965 brought unfamiliar religious and spiritual practices to the United States that found their way into popular culture.

- In the 1960s, renewing arguments first introduced by European philosophers in the late 19th century, a number of prominent theologians argued that "God Is Dead," that is, the Christian God was no longer a credible organizing idea for a moral life.

- New Age Spirituality, originating in 1960s England, migrated to the United States, gaining a foothold among those who were increasingly dissatisfied with the traditional Judeo-Christian cultural consensus.

- The Human Potential movement began in the 1960s. Reacting to traditional psychology and religion and finding a basis in Maslow's hierarchy of needs, this movement emphasized processes and therapies that focused on the self and were holistic in their approach to wellness and personal transformation involving body, mind, and spirit.

- A dissatisfaction with perceived shortcomings of value-free objectivity claimed by science led some to explore "alternative ways of knowing" apart from the positivism of normal science's knowledge-by -accumulation.

These ideas combined in a zeitgeist that seemed to enable an alternative vision for personal meaning and flourishing that could be found apart from religion (Waggoner, 2011). 
Building on these trends, the way had been prepared further by the 1990 s for a more open treatment of spirituality in higher education by the writings of Parker Palmer. Nearly single handedly, he introduced a contemporary concept of the idea of "education as a spiritual journey" in his 1983 book (reprinted and more widely circulated in 1993), To Know As We Are Known: Education As a Spiritual Journey (Palmer, 1993). His contributions reflected in this book were recognized that same year by the Council of Independent Colleges with the award for Outstanding Service to Higher Education.

The signature event that initiated this new emphasis on spirituality in higher education came in October 1998 with a conference at Wellesley College organized by Victor Kazanjian, new dean of religious and spiritual life at Wellesley, and Peter Laurence, co-founder with Kazanjian of the Education as Transformation Project. They planned for 300 attendees and had to cut off registration at 800, so great was the interest. Parker Palmer, Diana Eck, and many other leaders in thinking about religion and spirituality in higher education spoke to the gathering. A 2001 edited book by Kazajian and Laurence collected papers from these speakers and more to reflect the state of thinking at the outset of this movement (Kazajian \& Laurence, 2000).

In 1999, the first treatment of spirituality appeared in a major peer-reviewed academic journal in higher education, Patrick Love and Donna Talbot's article in the NASPA Journal, "Defining Spiritual Development: A Missing Consideration in Student Affairs" (Love \& Talbot, 1999). Calling for attention to this neglected dimension of student development theory, they cited the founding documents of the student affairs profession in 1937, where a commitment was made to consider the student as a whole, including moral and religious values (American Council on Education, 1937, 1949). Love and Talbot also developed a five part definition for spirituality that involved: (a) searching for personal authenticity and wholeness, (b) transcending the self, (c) connecting to self and others, (d) finding meaning and purpose, and (e) relating to the transcendent.

That same year a book appeared by Robert J. Nash, Faith, Hype and Clarity: Teaching about Religion in America's Schools and Colleges (Nash, 1999). Though it received less attention at first than Love and Talbot, Nash made a fuller case for the same issue, distinguishing religion-less spirituality as a legitimate alternative for morality. Nash would go on to write several books and articles in the service of the new emphasis on spirituality as part of holistic development.

2000 brought the publication of what would come to be considered one of the most important books for conceptualizing the spiritual development of emerging adults, Sharon Daloz Parks' Big Questions, Worthy Dreams: Mentoring Young Adults in their Search for Meaning, Purpose, and Faith. A student and colleague of James Fowler, author of the seminal work, Stages of Faith: The Psychology of Human Development and the Quest for Meaning, Parks extended Fowler's model of faith development with a additional nuanced phase for emerging adults including college students (Fowler, 1981; Parks, 2010). From this point forward the literature on spirituality and religion began to grow rapidly. The Journal of College \& Character figured prominently in furthering this discussion by way of articles and two regular columns on spirituality and interfaith dialogue, as did the Institute on College Student Values ${ }^{1}$ that featured speakers such as Sharon Daloz Parks, Alexander and Helen Astin, Parker Palmer, and Cornel West.

It soon became clear to leading higher education scholars, Alexander and Helen Astin, that this burgeoning field needed better data to understand how college students thought about these issues in relation to their own development. Building on their many years of research on college students through the

\footnotetext{
${ }^{1}$ The name of the Institute on College Student Values was changed to the Jon C. Dalton Institute on College Student Values in 2010. It is named after Jon C. Dalton, who founded the Institute in 1990, when he was vice president of student affairs at Florida State University.
} 
UCLA Higher Education Research Institute, the Astins led a team through a seven-year study (2003-2009) surveying a nationally representative sample of more than 14,000 students to ascertain the extent to which spirituality figures in the life of emerging adults (http://spirituality.ucla.edu/). Their book, Cultivating the Spirit: How College Can Enhance Students' Inner Lives, reported these results, and they are discussed in the following (Astin, Astin, \& Lindholm, 2011).

Given the fact that faculty plays a central role in teaching and learning interactions with students, it seemed a natural step to study faculty attitudes in this same area. This process also began with a study by the Astins in 1999 . Jennifer Lindholm joined the team as they fully implemented in their spirituality and higher education study with a survey of faculty in 2004-2005 and then followed in 2012 with the Faculty Beliefs and Values Survey. Lindholm's 2014 book reported these findings, and they are discussed below (Lindholm, 2014).

One further major research product came from this UCLA project, an edited volume of nine in-depth studies commissioned from a national competition (Rockenbach \& Mayhew, 2013a). These studies fell into three categories: student characteristics and group differences, college contexts, and outcomes. Selected findings from these studies will also be reviewed in the following.

\section{What We Think We Know About Spirituality and College Students and Faculty}

Inasmuch as numerous books, book chapters, and articles have emerged from research in this area over the last 15 years, what follows are selective highlights of what has been learned. Readers are strongly encouraged to go to the sources to benefit from the nuanced work referenced here.

\section{UCLA Spirituality and Higher Education Study}

The UCLA research team organized their findings relative to spirituality and college students around five qualities: equanimity, spiritual quest, ethic of caring, charitable involvement, and ecumenical worldview. Overall, students continue to grow spiritually during college, though their overtly religious activities may actually decrease. A major contributor to this spiritual growth is work related to the "inner selves" of students. Self-reflection and meditation are key vehicles to facilitate this attention to the self, and these practices, in combination with exposure to diversity, enhance students' ability to appreciate multiple perspectives. Experience with diversity may come in several forms, including international study abroad, interdisciplinary study, and contact with differing people and cultures. This spiritual development contributes to students' self-confidence and academic and leadership skills, as well as their satisfaction with college. More specific gains may be seen within each of the following five measures.

Equanimity means the ability of a person to find meaning in life with the concomitant result of being at relative peace with who and where they are and the general direction of things. This ability is perhaps the fundamental orienting disposition for the college student as it impacts feelings and behaviors and therefore more downstream outcomes including grades, relationships, satisfaction with college, and general sense of well-being. There is significant growth for undergraduates in this area through their college years.

Spiritual quest involves the active search for meaning, so the degree of commitment to this work determines the outcome. Students' interest in spiritual quest generally grows through college. The extent to which they grow depends upon personal motivation, and contributors to that motivation may be faculty who encourage such exploration in and out of class. Involvement in service activities, religious practice, and, as with equanimity, self-reflection and meditation can contribute. 
Ethic of caring is the internal attitude toward the situation of others, an empathetic concern to alleviate detrimental conditions. This is a concern for social justice and the welfare of those in need. It is the inner sense that drives the outer action. This dimension of the spiritual also grows during college. As might be expected, it can be facilitated by service learning work but also by exposure to diversity through study abroad or contact with people and cultures different than their own where they go to school. Living on campus may also contribute to an ethic of caring, particularly when the campus is multi-culturally diverse.

Charitable involvement is the action side of the ethic of caring; it involves doing. Three aspects of such involvement contribute to positive student outcomes: community service, charitable financial contributions, and assisting friends with personal problems. Involvement in student organizations, fraternities and sororities, leadership training, and living on campus all contribute positively to growth in this spiritual dimension. Charitable involvement appears to be an indicator of health in the areas of equanimity and ethic of caring.

Ecumenical worldview involves the ability to transcend one's own position and perspective and appreciate the values and beliefs of others. Growth in this area is seen in feelings of interconnectedness on a broad human scale and a respect for other religious and non-religious approaches to the "big questions." This spiritual dimension may be enhanced when faculty directly encourage students to engage with other viewpoints, to explore questions of meaning, and to engage in self-reflection and mediation. Students also grow in this area through living on campus and through interactions with different races and cultures (Astin et al., 2011). More research is currently underway on this dimension and will be discussed in the following.

\section{Faculty Beliefs and Values Survey}

As mentioned earlier, faculty spirituality was also studied in this and subsequent research. The 2012 Faculty Beliefs and Values Survey was built upon the earlier HERI 2004-5 Triennial Survey of College Faculty as well as the 2004 and 2007 College Students Values and Beliefs Surveys. Of those participating were 8,447 tenure-track faculty in 264 colleges and universities across the United States. Compared to the general U.S. population, faculty are less likely to identify as religious though are on par with the larger population when identifying as spiritual. Faculty identifying as spiritual and religious number $57 \%$. Those spiritual but not religious: $21 \%$. Nineteen percent indicated neither religious nor spiritual, with $2 \%$ saying they were religious but not spiritual. More than $80 \%$ felt that their professional and spiritual lives were at least somewhat integrated, and more than half reported a sense of calling in their work. They were, however, quite divided as to whether the undergraduate experience was an appropriate place for addressing student spiritual development head on. While $77 \%$ agreed that the campus life should contribute to personal and professional development, more than half disagreed that spiritual development should be included in the mix; that number rises to $77 \%$ when considering only public institution faculty.

The potential for influence upon students in the area of spiritual development by faculty is significant as indicated, in part, in the above discussion of student spiritual development. When faculty encourage exploration of questions of meaning, introduce self-reflection and meditation in the classroom, model alternative viewpoints with integrity and respectfully, and are available for mentoring, positive outcomes for students increase in most every area: grades, satisfaction with college, intellectual self-confidence, and increases in all five measures of spiritual development. The conundrum is that even with these apparent positive outcomes, most faculty are reticent to engage with students on matters that may be associated with spirituality. Among the reasons for this may be fear of criticism by colleagues and perceived lack of knowledge to deal with the potential range of possible issues that may arise from such interactions (Lindholm, 2014). 


\section{Commissioned Studies from the UCLA Database}

In 2008 the UCLA Spirituality in Higher Education project conducted a competition for researchers to propose original work that made use of their extensive database. Of the 68 proposals received, 12 were funded. Most of those studies were then published in the book edited by Alyssa Rockenbach and Matthew Mayhew, referenced earlier in this article (Rockenbach \& Mayhew, 2013a). The work of these scholars extended the findings on college students and spirituality by narrowing the foci of their research. Following are some of the essential findings from that body of work as they addressed student characteristics and group differences, college contexts, and outcomes.

\section{Student Characteristics and Group Differences}

Bowman and Small studied religious minorities and what conditions contributed to and detracted from their spiritual growth. They found that acknowledgement of their identities by their institution and attention to activities that recognized, engaged, and supported their identities, combined with faculty support, contributed to their spiritual growth. Absence of those conditions could exacerbate feelings of marginalization and undercut spiritual development during college (Bowman \& Small, 2013).

Gehrke's study analyzed racial differences in spiritual development in college concluding that students from different racial/ethnic backgrounds have differing levels of and expectation for spiritual development entering college and three years later. Black students grow in spiritual identification and spiritual quest during college but not in equanimity. Asian students grow significantly in all three dimensions, with growth in equanimity being attributed to pro-social involvement. The experience of Latino students is closer to Asian students as all three dimensions grow in college. It is not as clear, however, what contributes to equanimity (Gehrke, 2013). Similar to the Bowman and Small findings, the greater the institutional attention to group identities, the greater the opportunity for spiritual growth across all dimensions.

\section{College Contexts}

Rine studied Christian college students in the context of the challenge of maintaining exclusivist truth claims in a postmodern culture. From this he developed a fallibilist model for Christian higher education that helps negotiate a delicate balance involving provisionality in holding one's beliefs in an encounter with new information that provokes dissonance with prior beliefs. He suggests empirically based institutional measures for supporting student spiritual growth and institutional persistence with integrity (Rine, 2013).

Rockenbach and Mayhew deepen aspects of the original UCLA study of the ecumenical worldview dimension of spirituality. With respect to institutional contexts, they found religious affiliation important. Catholic colleges tended to foster an ecumenical worldview more that evangelical Christian colleges, and in all cases, the peer environment was influential: The more students reported spiritual struggles and ecumenical perspectives, the greater the opportunity for ecumenical worldview development throughout the student body. Regarding institutional practices, curricular and co-curricular practices that directly engage students with questions of religion and spirituality, particularly with faculty, result in opportunity for ecumenical worldview development. Finally, there are differences in ecumenical worldview development by gender, race/ethnicity, and worldview. "Women, racial/ethnic minority students, and religious minority students exhibit higher levels of ecumenism than do men, racial/ethnic majority students, religious majority students, and non-religious students" (Rockenbach \& Mayhew, 2013b, p. 100). Rockenbach 
and Mayhew are currently continuing worldview research with the Interfaith Diversity Experiences \& Attitudes Longitudinal Study (IDEALS) (www.ifyc.org/ideals).

\section{Outcomes}

Four themes relating to pro-social development emerge from the studies in this section. First, students identifying as spiritual or religiously committed are more likely to experience growth in pro-social development along the dimensions of ethic of care, charitable involvement, and a compassionate self-concept (Brandenburg \& Bowman, 2013). Second, spirituality and religious commitment are antecedents to a social justice orientation with respect to attitudes and actions. Though the influences are reciprocal, students identifying as spiritual exhibit greater growth than the religiously committed (Chenot \& Kim, 2013). Third, student/faculty interaction in the areas of ethical/ spiritual concerns, academic/career issues, and student-centered pedagogy promotes development of the caring self as measured by growth in ethic of care (Fleming, Purnell, \& Wang, 2013). Finally, those experiencing spiritual struggles tend toward higher incidence of smoking, drinking, and drug abuse. Compassionate self-care mediates towards a decrease in these behaviors as does institutional type (religious affiliated have lower incidence than secular publics) and co-curricular activities and programming (Faigin, 2013).

The foregoing suggests that there is sufficient interest in spirituality among students, faculty, and staff to warrant systematic attention on campus. Research indicates that there are positive outcomes for students when attention to spiritual development is addressed. While faculty may be reticent to engage in such discussions in academic settings, it is clearly within the purview of student affairs staff to address spirituality on any number of fronts from wellness to residence hall programming. One caveat as these initiatives are considered is the law. The courts have rendered decisions on the treatment of religion in higher education. Inasmuch as spirituality touches upon common areas with religion, such as individual beliefs and practices, it is important to review major legal parameters for public institutions. As I mentioned above, private colleges and universities, due to their voluntary contractual relationships with students, faculty, and staff, are not bound by law to the extent that public institutions are.

\section{Legal Considerations}

Neutrality, academic freedom, and nondiscrimination are the principal ideas elaborated by the courts with respect to treatment of religion in public colleges and universities; by extension, they should be considered in any attention to spirituality as well. The first amendment to the Constitution delineates freedoms guaranteed its citizens, the first of which are freedom from "establishment of religion" and the protection of the "free exercise of religion." The common objective of the combined clauses is to ensure government neutrality in the treatment of religion. Government must neither allow the tenets of a particular religious tradition to have the force of law nor constrain individual free exercise of religion. Adjudicating conflicting views among the public, particularly in the area of free exercise in combination with free speech, is arguably a leading area of contemporary jurisprudence with respect to religion.

How one chooses to interpret neutrality is part of the issue. One may opt for a "total abstinence" perspective that invokes a strict application of separation of church and state: no religion or spirituality allowed within public institutions. Or, one may opt for "fairness" perspective of neutrality that, with an eye toward the free exercise and free speech protections, seeks an even hand in accommodating religion and spirituality in public institutions. Though some believe the former should be the case, deriving from 
Thomas Jefferson's famous phrase about a "wall of separation between church and state," the court has ruled that generally the latter is more constitutionally appropriate (Jefferson, 1802).

\section{Academic Freedom and Nondiscrimination}

\section{Academic Freedom}

Evolving law decisions from the Dartmouth case forward established public higher education as a distinct environment from both private higher education and public schools (Trustees of Dartmouth College v. Woodward, 17 U.S. 518 [1819]). Two overarching concepts combine to guide this evolution: academic freedom and the marketplace of ideas, and nondiscrimination deriving from neutrality. The courts have held that public higher education is a unique environment in which competing ideas should be free to be tested, and no person or organization should be discriminated against in the process of this exercise of academic freedom. Religious activities became a major test of the constitutional viability of these ideas.

\section{Nondiscrimination}

The Fourteenth Amendment to the Constitution, ratified nearly 150 years ago, remains among the most litigated parts of the Constitution, particularly the due process and equal protection clauses. The federal Fourteenth Amendment, as well as comparable state constitutional provisions, applies to public higher education institutions; consequently, those colleges and universities must draft policies governing institutional life in ways that do not breach the rights of its students, staff, and faculty. Federal civil rights laws may also pertain, though grounds of sexual orientation and religion are not covered by these statutes. The initial challenges of discrimination were raised with respect to sex and race. Most recently, however, religious discrimination has generated the most controversy. As questions arise in policy development, it would be prudent to consult legal counsel (Waggoner, in press).

\section{Selected Contemporary Practices}

As might be expected, the ways in which contemporary higher education addresses religion and spirituality range widely from not at all to varying depths. Private, religiously affiliated institutions, as noted previously, have done this since their inception with most loosening their strict doctrinal statements and behavioral codes while still retaining openness to discussion and practice. It is among the public colleges and universities, however, where one must look to see the extent to which spirituality is making inroads. Recent research indicates some increase in addressing spirituality in this sector.

Among the 570 Carnegie-classification, public, four-year colleges and universities in the United States, slightly more than half reference religion or spirituality among their resources. There are 23 institutions among this number with specific organizational entities that have religion and spirituality as a primary mission. The remaining more than 300 institutions have an affiliative connection to units that are either independent of the institution (i.e., campus ministries) or are loosely connected with student life through the dean of students or student organizations. For example, a student affairs staff member may be assigned liaison responsibilities to campus ministries, or a list of student organizations may contain religious or spiritual groups that operate with institutional support (i.e., facilities and student fees), but are not supervised or directed by institutional staff.

The extent to which staff members assign responsibility for this area beyond the liaison role initiate programming varies by institution. It is often at the initiative of the individual and as such may follow her 
personal inclinations or previous practices of the institution. For example, at the University of Northern Iowa (UNI), there is a student affairs staff member who has, among other responsibilities, the liaison role to the campus ministers. Additionally she coordinates a session for the summer orientation for parents and new students called "Spiritual Connections," in which campus resources for religious and spiritual development are shared. This session was originated before her coming to UNI, and she is continuing it. These types of arrangements are most common. It is the independent dedicated entities that are the most unusual.

The largest and most prominent of this type of public university unit is the Pasquerilla Spiritual Center at Penn State University. It has its own facility and hosts and conducts a range of programs from traditional campus ministries to interfaith and non-religious spirituality. There are a growing number of such units-more than 20 nationally - that are attempting to respond to this long neglected aspect of the whole student but also to the increasing numbers of students who are requesting space to conduct their respective religious or spiritual practices. Another such unit may be found at the University of Florida in its Center for Spirituality and Health. Its mission is to pursue research and provide curriculum at the interface of spirituality and the health sciences.

There is yet another approach to addressing moral issues on campus that is emerging under the name of secular programs. Because of existing assumptions that the moral life may be pursued and understood apart from religion and spirituality, there is an increase in chaplains and other staff members who are working from atheist or humanist perspectives to serve a population for whom religion and spirituality are not helpful resources (Kolowich, 2009; Harvard Chaplains, n.d.).

\section{Conclusion}

Higher education's concern for the whole student may be said to date from its inception in British colonial America as religious institutions sought to furnish the minds and save the souls of its students. As these institutions transformed over the ensuing centuries, most became more secular. In recent decades, however, many in higher education have sought to restore the place of religion in the overall work of the university but also add the place of spirituality not based on religion into the mix of services that aid in the process of developing the whole student. A research base has established the potential value of such an enterprise, but, with the exception of a small number of initiatives, it remains for college and university leadership to choose to develop coherent institutional plans to advance campus climates wherein the spiritual development of students may be cultivated.

\section{References}

American Council for Education. (1937, 1949). The student personnel point of view. Washington, DC: American Council on Education.

Astin, A., Astin, H., \& Lindholm, J. A. (2011). Cultivating the spirit: How college can enhance students' inner lives. San Francisco, CA: Jossey-Bass.

Barnes, J. (2002). Early Greek philosophy. London, UK: Penguin Books.

Bowman, N. A., \& Small, J. L. (2013). The experiences and spiritual growth of religiously privileged and religiously marginalized college students. In A. B. Rockenbach \& M. J. Mayhew (Eds.), Spirituality in college students' lives: Translating research into practice (pp. 19-34). New York, NY: Routledge.

Brandenburg, J. W., \& Bowman, N. A. (2013). From faith to compassion? Reciprocal influences of spirituality, religious commitment, and prosocial development during college. In A. B. Rockenbach \& M. J. Mayhew (Eds.), Spirituality in college students' lives: Translating research into practice (pp. 121-137). New York, NY: Routledge. 
Chenot, D., \& Kim, H. (2013). Development among adolescents and young adults: Longitudinal linkages between spirituality, religion, and social justice. In A. B. Rockenbach \& M. J. Mayhew (Eds.), Spirituality in college students' lives: Translating research into practice (pp. 138-152). New York, NY: Routledge.

Faigin, C. A. (2013). Informing effective psychospiritual interventions for college students: Identifying mediators in the relationship between spiritual struggles and substance abuse. In A. B. Rockenbach \& M. J. Mayhew (Eds.), Spirituality in college students' lives: Translating research into practice (pp. 170-187). New York, NY: Routledge.

Fleming, J. J., Purnell, J., \& Wang, Y. (2013). Student-faculty interaction and the development of an ethic of care. In A. B. Rockenbach \& M. J. Mayhew (Eds.), Spirituality in college students' lives: Translating research into practice (pp. 153-169). New York, NY: Routledge.

Fowler, J. W. (1981). Stages of faith: The psychology of human development and the quest for meaning. San Francisco, CA: HarperSanFrancisco.

Gehrke, S. (2013). Race and pro-social involvement: Toward a more complex understanding of spiritual development in college. In A.B Rockenbach \& M.J. Mayhew (Eds.), Spirituality in college students' lives: Translating research into practice (pp. 35-48). New York, NY: Routledge.

Harvard Chaplains. (n.d.) Humanist chaplancy (Humanist/Agnostic/Athiest). Retrieved from chaplains.harvard.edu/filter_ by/humanist-chaplaincy-humanistagnosticatheist1

Jacobsen, D., \& Jacobsen, R. H. (2012). No longer invisible: Religion in university education. New York, NY: Oxford University Press.

Jefferson, T. (1802). Letter to the Danbury Baptists. Retrieved from www.loc.gov/loc/lcib/9806/danpre.html.

Kazanjian, V. H., \& Laurence, P. L. (2000). (Eds). Education as transformation: Religious pluralism, spirituality, and a new vision for higher education in America (3rd ed.). New York, NY: Peter Lang.

Kolowich, S. (2009). Humanist chaplains. Inside Higher Ed. Retrived from www.insidehighered.com/news/2009/11/12/ chaplain

Lindholm, J. A. (2014). The quest for meaning and wholeness: Spiritual and religious connections in the lives of college faculty. San Francisco, CA: Jossey-Bass.

Lipka, M. (2015). A closer look at America's rapidly growing religious 'nones.' Retrieved from http://www.pewresearch.org/ fact-tank/2015/05/13/a-closer-look-at-americas-rapidly-growing-religious-nones/

Love, P., \& Talbot, D. (1999). Defining spiritual development: A missing consideration for student affairs. NASPA Journal, 37(1), 361-376. doi:10.2202/0027-6014.1097

Nash, R. J. (1999). Faith, hype, and clarity: Teaching about religion in American schools and colleges. New York, NY: Teachers College.

Palmer, P. J. (1993). To know as we are known: Education as a spiritual journey. San Francisco, CA: HarperSanFrancisco.

Parks, S. D. (2010). Big questions, worthy dreams: Mentoring young adults in their search for meaning, purpose, and faith. San Francisco, CA: Jossey-Bass.

Rine, P. J. (2013). Christian college persistence in the postmodern turn. In A. B. Rockenbach \& M. J. Mayhew (Eds.), Spirituality in college students' lives: Translating research into practice (pp. 69-87). New York, NY: Routledge.

Rockenbach, A. B., \& Mayhew, M. J. (Eds.). (2013a). Spirituality in college students' lives: Translating research into practice. New York, NY: Routledge.

Rockenbach, A. B., \& Mayhew, M. J. (2013b). How institutional contexts and college experiences shape ecumenical and worldview development. In A. B. Rockenbach \& M. J. Mayhew (Eds.), Spirituality in college students' lives: Translating research into practice (pp. 88-104). New York, NY: Routledge.

Trustees of Dartmouth College v. Woodward, 17 U.S. 518 (1819).

Waggoner, M. D. (2011). Sacred and secular tensions in contemporary higher education. In M. D. Waggoner (Ed.), Sacred and secular tensions in higher education: Connecting parallel universities (pp. 1-17). New York, NY: Routledge.

Waggoner, M. D. (in press). Universities and colleges, public. In C. Russo (Ed.), Religion in American education: A legal encyclopedia. Lanham, MD: Rowman \& Littlefield. 